\title{
Comparative Efficacy of Once-Daily Umeclidinium/ Vilanterol and Tiotropium/Olodaterol Therapy in Symptomatic Chronic Obstructive Pulmonary Disease: A Randomized Study
}

\author{
Gregory J. Feldman · Ana R. Sousa - David A. Lipson - Lee Tombs · \\ Neil Barnes · John H. Riley · Sadhana Patel · Ian Naya • \\ Chris Compton · Bernardino Alcázar Navarrete
}

Received: August 24, 2017 / Published online: November 1, 2017

(C) The Author(s) 2017. This article is an open access publication

\begin{abstract}
Introduction: We report the results of the first direct comparison of the once-daily fixed-dose long-acting muscarinic antagonist/long-acting $\beta_{2}$-agonist (LAMA/LABA) combinations
\end{abstract}

Enhanced Content To view enhanced content for this article go to http://www.medengine.com/Redeem/ 23CCF06051209CED.

Electronic supplementary material The online version of this article (doi:10.1007/s12325-017-0626-4) contains supplementary material, which is available to authorized users.

\section{G. J. Feldman ( $\square)$}

S. Carolina Pharmaceutical Research, Spartanburg, SC, USA

e-mail: gfeld3232@aol.com

\section{A. R. Sousa}

Respiratory Research and Development,

GlaxoSmithKline, Stockley Park West, Uxbridge,

Middlesex, UK

D. A. Lipson

Respiratory Research and Development,

GlaxoSmithKline, King of Prussia, PA, USA

D. A. Lipson

Perelman School of Medicine, University of

Pennsylvania, Philadelphia, PA, USA

L. Tombs

Precise Approach Ltd, Birmingham, West Midlands,

UK umeclidinium/vilanterol (UMEC/VI) and tiotropium/olodaterol (TIO/OLO) in patients with COPD.

Methods: This was a randomized, two-period crossover open-label study in symptomatic patients with COPD [age 40 years or older, postbronchodilator forced expiratory volume in $1 \mathrm{~s}\left(\mathrm{FEV}_{1}\right)$ of $70 \%$ or less and $50 \%$ or more of predicted normal values, and modified Medical Research Council Dyspnoea Scale score of 2 or greater] not receiving inhaled corticosteroid therapy. Patients were randomized to receive UMEC/VI (62.5/25 $\mu \mathrm{g}$ once daily) via a multidose dry powder inhaler (ELLIPTA) followed by TIO/OLO (5/5 $\mu$ g once daily) via a soft mist

\author{
N. Barnes · S. Patel · C. Compton \\ Global Respiratory Franchise, GlaxoSmithKline, \\ Brentford, Middlesex, UK \\ J. H. Riley \\ Respiratory Therapy Area Unit, GlaxoSmithKline \\ Medicines Research Centre, GlaxoSmithKline, \\ Stevenage, Hertfordshire, UK \\ I. Naya \\ Respiratory Medicine, GlaxoSmithKline, Brentford, \\ Middlesex, UK \\ B. Alcázar Navarrete \\ Neumología, Hospital de Alta Resolución de Loja, \\ Granada, Spain
}


inhaler (Respimat), each for 8 weeks with an interim 3-week washout or vice versa. The primary end point was the change from baseline in trough $\mathrm{FEV}_{1}$ at week 8 with a noninferiority margin of $-50 \mathrm{~mL}$ in the per-protocol (PP) population. The incidence of adverse events was also assessed.

Results: In total, 236 patients (mean age 64.4 years, $60 \%$ male) were included in the intent-to-treat population and 227 were included in the PP population. UMEC/VI treatment was noninferior in the PP population and superior in the intent-to-treat population to $\mathrm{TIO} / \mathrm{OLO}$ treatment with regard to trough $\mathrm{FEV}_{1}$ at week $8\left[\mathrm{FEV}_{1}\right.$ change from baseline $180 \mathrm{~mL}$ vs $128 \mathrm{~mL}$; difference $52 \mathrm{~mL}$ (95\% confidence interval $28-77 \mathrm{~mL}) ; p<0.001]$. Patients receiving UMEC/VI had twofold increased odds of experiencing a clinically meaningful increase (100 mL or more) from baseline in trough $\mathrm{FEV}_{1}$ at week 8 compared with patients receiving TIO/OLO (odds ratio 2.05; 95\% confidence interval 1.34-3.14). Adverse events occurred in $25 \%$ of patients in the UMEC/VI group and in $31 \%$ of patients in the TIO/OLO group.

Conclusion: In this first direct comparison of two once-daily fixed-dose LAMA/LABA combinations, superiority was observed for the primary end point of trough $\mathrm{FEV}_{1}$ at week 8 with UMEC/VI compared with TIO/OLO in patients with symptomatic COPD. Both treatments had similar safety profiles. These findings confirm the results of previous indirect LAMA/LABA comparisons, and show that an efficacy gradient exists within the LAMA/LABA class.

Trial Registration: ClinicalTrials.gov identifier NCT02799784.

Funding: GlaxoSmithKline.

Keywords: Bronchodilation; COPD; LAMA; LABA; Long-acting muscarinic antagonist; Long-acting $\quad \beta_{2}$-agonist; $\quad$ Olodaterol; Tiotropium; Umeclidinium; Vilanterol

\section{INTRODUCTION}

Chronic obstructive pulmonary disease (COPD) is one of the leading global causes of death and morbidity, and presents a considerable economic burden to healthcare systems worldwide [1-4]. The cornerstone of pharmacological therapy for COPD is bronchodilation, with a long-acting muscarinic antagonist (LAMA), a long-acting $\beta_{2}$-agonist (LABA), or a combination of the two [5-7].

Bronchodilator therapy has been shown to improve lung function, decrease the severity of symptoms, and reduce the risk of future exacerbations in COPD [4]. The efficacy of the LAMA umeclidinium (UMEC), $62.5 \mu \mathrm{g}$, was recently shown to be superior to that of the widely used tiotropium (TIO), $18 \mu \mathrm{g}$, with a significant increase in trough forced expiratory volume in $1 \mathrm{~s}\left(\mathrm{FEV}_{1}\right)$ after 12 weeks of monotherapy [8]. Multiple randomized controlled trials have demonstrated greater improvements in lung function and patient-reported outcomes, including exacerbations, with LAMA/LABA combinations compared with LAMA or LABA monotherapies in patients with stable COPD [9-15]. To date, no direct comparative trials have examined the efficacy and safety differences between the once-daily LAMA/LABA combinations. As such, it remains unclear whether the efficacy differences between once-daily UMEC and TIO monotherapies would still be present when they are administered as a component of a dual LAMA/LABA bronchodilator therapy.

Indirect evidence from network metaanalyses suggests a potential gradient of effectiveness may exist, at least with regard to lung function [16-18]. Because of the limitations of indirect treatment comparisons, however, data from direct head-to-head comparisons are required to confirm these findings.

This study is the first direct comparison of the two once-daily fixed-dose LAMA/LABA combinations UMEC/vilanterol (VI), $62.5 / 25 \mu \mathrm{g}$, delivered via a multidose dry powder inhaler (ELLIPTA, a registered trademark of the GlaxoSmithKline group of companies), and TIO/olodaterol (OLO), 5/5 $\mu \mathrm{g}$, delivered via a soft mist inhaler (Respimat, a registered trademark of Boehringer Ingelheim). These combination therapies are the only LAMA/LABA combinations approved in both the USA and Europe as once-daily maintenance therapies for COPD $[19,20]$. The primary objective of this 
8-week study was to evaluate the magnitude of lung function improvements in patients receiving UMEC/VI or TIO/OLO who had sufficient COPD symptoms to justify the use of dual bronchodilator therapy [4]. The safety of both treatments was also assessed.

\section{METHODS}

\section{Study Design}

This was an 8-week, multicenter, randomized, open-label, two-period crossover, complete-block design study (NCT02799784; GlaxoSmithKline clinical study identifier 204990) conducted in centers across Germany, Spain, the UK, and the USA between July 2016 and April 2017.

The study was conducted in accordance with International Conference on Harmonisation of Technical Requirements for Registration of Pharmaceuticals for Human Use good clinical practice guidelines and the principles of the Declaration of Helsinki. The protocol was reviewed and approved by all appropriate institutional review boards or independent ethics committees [Ethik-Komission (Germany), Comité Ético de Investigación (Spain), Chesapeake IRB (USA), and United Kingdom Ethics Committee]. All patients provided written informed consent before study participation.

\section{Patients}

Key eligibility criteria for enrollment in the study were as follows: an outpatient aged 40 years or older with a diagnosis of COPD in accordance with the American Thoracic Society/European Respiratory Society definition [21]; a current or former smoker with a smoking history of 10 pack-years or more; a prebronchodilator and postbronchodilator $\mathrm{FEV}_{1}$ /forced vital capacity (FVC) ratio less than 0.70 ; a postbronchodilator $\mathrm{FEV}_{1}$ of $70 \%$ or less and $50 \%$ or more of predicted normal values at visit 1 [22]; and a score of 2 or more on the modified Medical Research Council Dyspnoea Scale [23] at visit 1 . Key exclusion criteria were as follows: the presence of any major respiratory disease other than COPD; the use of inhaled corticosteroid (ICS) treatment in the 30 days before screening; and a moderate/severe exacerbation or lower respiratory tract infection during the run-in period. Full inclusion and exclusion criteria are presented in the electronic supplementary material.

Maintenance medications for COPD (other than the study medication) were not permitted during any period of the study. This included LAMAs, LABAs, oral $\beta$-agonists, theophyllines, ICS, and phosphodiesterase 4 inhibitors. As-needed use of supplemental albuterol was permitted throughout the study to provide additional symptomatic relief (though not in the $4 \mathrm{~h}$ before spirometry testing). A full list of the medications permitted during the study is presented in Table $\mathrm{S} 1$.

\section{Randomization and Treatment}

After a 2-week run-in period, eligible patients were randomized (with use of the RAMOS automated randomization system) to receive either open-label UMEC/VI $(62.5 / 25 \mu \mathrm{g})$ administered once daily via the ELLIPTA inhaler (via one puff) or open-label TIO/OLO $(5 / 5 \mu \mathrm{g})$ administered once daily via the Respimat inhaler (via two puffs of $2.5 / 2.5 \mu \mathrm{g}$ ) for 8 weeks. This was followed by a 3-week washout, after which the treatments were switched for a second 8-week treatment period (Fig. 1). Outside study visits, patients self-administered their study medications according to written instructions provided; on visit days, patients were asked to withhold administration of their medication until instructed to administer it. Proper administration of study treatment was evaluated at study visits, and compliance was assessed at weeks 4 and 8 by review of the dose counter on the ELLIPTA inhaler, or the number of inhalations per day as recorded in the eDiary for the Respimat inhaler. Patients with compliance less than $80 \%$ or greater than $120 \%$ were required to be reeducated on proper dosing. Treatments had to be administered open-label as placebo Respimat inhalers were not available from Boehringer Ingelheim. 


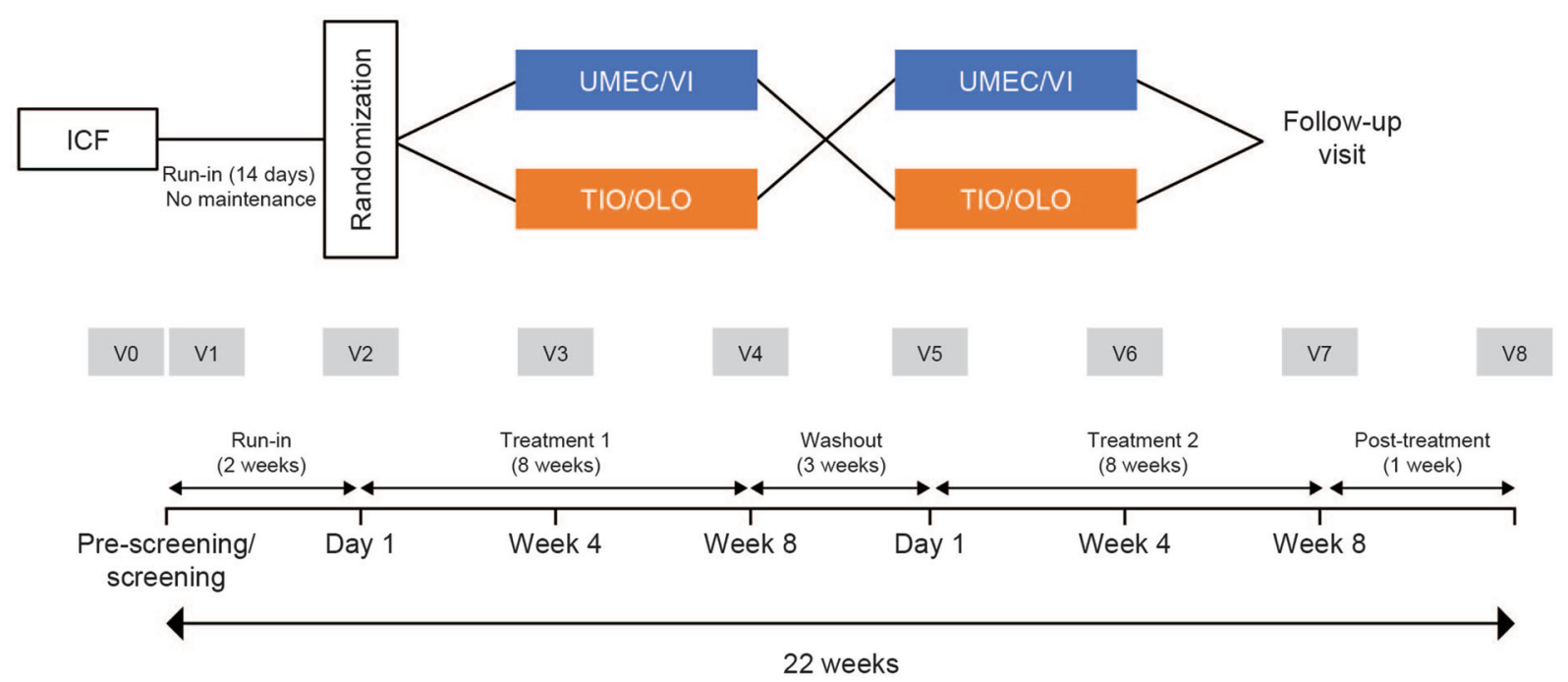

Fig. 1 Study design. ICF informed consent form, TIO/OLO tiotropium/olodaterol $(5 / 5 \mu \mathrm{g})$, UMEC/VI umeclidinium/ vilanterol $(62.5 / 25 \mu \mathrm{g})$, $\mathrm{V}$ study visit

However, all technicians performing spirometry were blinded to treatment allocation throughout the study. A final 1-week posttreatment follow-up visit was conducted to assess safety end points.

\section{End Points}

The primary efficacy end point of the study was the change from baseline in trough $\mathrm{FEV}_{1}$ at week 8 in the per-protocol (PP) population. Other end points assessed were (1) the proportion of $\mathrm{FEV}_{1}$ responders at week 8 (defined as a change from baseline of $100 \mathrm{~mL}$ or more); (2) trough $\mathrm{FEV}_{1}$ at week 4; (3) trough FVC at weeks 4 and 8 ; (4) trough inspiratory capacity (IC) at weeks 4 and 8 (derived with spirometry); (5) the use of rescue albuterol therapy (mean inhalations per day and the percentage of rescue medication-free days) captured with an eDiary; COPD Assessment Test (CAT) score [24] at weeks 4 and 8 ; (6) the proportion of CAT responders (defined as a decrease of 2 units or more from baseline) at weeks 4 and 8 ; (7) daily respiratory symptoms assessed with the Evaluating Respiratory Symptoms-COPD (E-RS $\left.\mathrm{COPD}_{\mathrm{CO}}\right)$ scale and its subscales (breathlessness, cough and sputum, and chest symptoms) $[25,26]$; (8) the proportion of $\mathrm{E}-\mathrm{RS}_{\mathrm{COPD}}$ responders (defined as a decrease of 2 units or more from baseline [25]); and (9) ease of inhaler use as assessed by investigator-administered questionnaires. Baseline spirometry data, lung function, eDiary assessments, and health status (as measured by

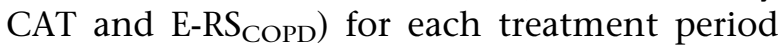
were obtained before administration of the first dose of the study medication for the treatment period, at visits 2 and 5 (Fig. 1).

Safety end points included the incidence of adverse events (AEs), serious AEs (SAEs), and COPD exacerbations. A moderate exacerbation was defined as worsening of symptoms requiring the use of antibiotics or systemic corticosteroids, and a severe exacerbation was defined as a worsening of symptoms requiring hospitalization or an emergency department visit lasting more than $24 \mathrm{~h}$. Clinical laboratory parameters and vital signs were also monitored.

\section{Study Population}

The intent-to-treat (ITT) population comprised all patients randomized to treatment and who therefore received at least one dose of the study medication. The PP population comprised all patients in the ITT population who did not have protocol deviations considered to have the potential to impact efficacy. The primary end 
point is presented for both the PP population and the ITT population; noninferiority analyses are presented for the PP population, and superiority analyses, other spirometry end points, patient-reported outcomes, and safety end points are presented for the ITT population.

In addition, an inhaler-naïve subpopulation was defined as all patients randomized to treatment who did not have a history of using either the ELLIPTA or the Respimat inhaler device. Patient preference data regarding inhaler ease of use are presented for the inhalernaïve population.

\section{Statistical Analysis}

Sample size calculations used a one-sided 2.5\% significance level and an estimate of within-subject standard deviation of $140 \mathrm{~mL}$ for trough $\mathrm{FEV}_{1}$. An ITT population of 220 patients was calculated to have $90 \%$ power to detect the noninferiority of UMEC/VI compared with $\mathrm{TIO} / \mathrm{OLO}$ for trough $\mathrm{FEV}_{1}$, with use of a noninferiority margin of $-50 \mathrm{~mL}$ and assuming a true mean treatment difference of $0 \mathrm{~mL}$, a patient on-treatment withdrawal rate of $15 \%$, and the exclusion of $10 \%$ of patients from the primary PP analysis. The margin of noninferiority was set at $-50 \mathrm{~mL}$ as this represents $50 \%$ of the minimum clinically important difference in trough $\mathrm{FEV}_{1}$, and has consistently been used as a noninferiority margin in similar studies comparing long-acting bronchodilators in patients with COPD [8, 27-29].

Treatment differences are presented as least squares (LS) mean estimates with 95\% confidence intervals (CIs) and $p$ values. If noninferiority of UMEC/VI to TIO/OLO was demonstrated (i.e., if the lower boundary of the two-sided 95\% CI for the estimated treatment difference was greater than $-50 \mathrm{~mL}$ ), statistical superiority was then investigated. UMEC/VI would be considered to have efficacy superior to that of TIO/OLO on the primary end point if the lower boundary of the estimated treatment difference $95 \%$ CI was more than $0 \mathrm{~mL}$.

Lung function and CAT end points were assessed by mixed model repeated measures analysis, with treatment group (categorical) as the explanatory variable, and period baseline, mean baseline, period, and visit as covariates. Responder analyses for trough $\mathrm{FEV}_{1}$ and CAT end points (at weeks 4 and 8 ) were performed with a generalized linear mixed model with covariates of period baseline, mean baseline, period, treatment, visit, visit by period baseline, visit by mean baseline, and visit by treatment interaction. Rescue therapy use was also assessed by mixed model repeated measures analysis, but included covariates of period baseline, mean baseline, period, treatment, 2-weekly period, 2-weekly period by period baseline interaction, and 2 -weekly period by mean baseline interaction.

\section{RESULTS}

\section{Patient Disposition and Demographics}

In total, 443 patients were enrolled in the study, 421 attended the screening visit, and 236 were randomized to treatment and included in the ITT population. Of these, 227 (96\%) were included in the PP population, $75(32 \%)$ were included in the inhaler-naïve population, and 225 (95\%) completed the study. The reasons for withdrawal from the study were patient decision $(n=7,3 \%)$, loss to follow-up ( $n=2$, less than $1 \%), \operatorname{AE}(n=1$, less than $1 \%)$, and protocol deviation $(n=1$, less than $1 \%)$.

Baseline demographics and characteristics for the ITT population are shown in Table 1; similar results were observed in the PP population. Most patients in both groups fell within the $80-120 \%$ range of compliance [UMEC/VI, 227 (97.8\%); TIO/OLO, 208 (95.4\%)].

\section{Lung Function}

In the PP population, the baseline mean (standard deviation) trough $\mathrm{FEV}_{1}$ was 1539 (457) mL in the UMEC/VI group and 1603 (450) $\mathrm{mL}$ in the TIO/OLO group. A statistically significant increase in the primary end point of trough $\mathrm{FEV}_{1}$ change from baseline at week 8 was observed with UMEC/VI compared with $\mathrm{TIO} / \mathrm{OLO}$ in this population, meeting 
Table 1 Baseline patient demographics and clinical characteristics of the intent-to-treat (ITT) population

ITT population $(N=236)$

Age (years) ${ }^{a}$

$64.4(8.5)$

Male

$142(60 \%)$

Smoking status

Never

$1(<1 \%)$

Current

$125(53 \%)$

Former

$110(47 \%)$

Smoking pack-years ${ }^{\mathrm{a}}$

$50.2(25.52)$

Postbronchodilator $\mathrm{FEV}_{1}(\mathrm{~L})^{\mathrm{a}}$

$1.734(0.406)$

Postbronchodilator percentage of predicted $\mathrm{FEV}_{1}{ }^{\mathrm{a}}$

$59.6(5.6)$

Reversible to albuterol therapy ${ }^{\mathrm{b}}$

$86(36 \%)$

Exacerbation history in the 12 months before screening

Treated without OCS and/or antibiotics

$\geq 1$ requiring OCS/antibiotics

$33(14 \%)$

2 requiring OCS/antibiotics

$4(2 \%)$

Requiring hospitalization

$6(3 \%)$

\section{GOLD stage}

B

$224(95 \%)$

$\mathrm{D}$

$12(5 \%)$

Modified Medical Research Council Dyspnoea Scale score

$$
2
$$

$156(66 \%)$

3

$71(30 \%)$

4

$9(4 \%)$

Concomitant medical conditions ( $\geq 10 \%$ of patients)

Hypertension

$134(57 \%)$

Hypercholesterolemia

$114(48 \%)$

Cardiac disorders

$58(25 \%)$

Coronary artery disease

$43(18 \%)$

Arrhythmia

$13(6 \%)$

Congestive heart failure

$6(3 \%)$

Myocardial infarction

$0(0 \%)$

Diabetes

$48(20 \%)$

IN population ${ }^{\mathrm{c}}$

$75(32 \%)$ 
Table 1 continued

ITT population $(N=236)$

Respiratory medications before run-in

SABA $^{\mathrm{d}}$

$151(64 \%)$

LAMA

$38(16 \%)$

LABA

$29(12 \%)$

SAMA

$25(11 \%)$

ICS

$10(4 \%)$

LAMA/LABA ${ }^{\mathrm{e}}$

$30(13 \%)$

$F E V_{1}$ forced expiratory volume in $1 \mathrm{~s}, G O L D$ Global Initiative for Chronic Obstructive Lung Disease, ICS inhaled corticosteroid, IN inhaler naïve, $L A B A$ long-acting $\beta_{2}$-agonist, $L A M A$ long-acting muscarinic antagonist, $O C S$ oral corticosteroids, $S A B A$ short-acting $\beta_{2}$-agonist, $S A M A$ short-acting muscarinic antagonist

a The standard deviation is given in parentheses.

b Reversibility defined as an increase in $\mathrm{FEV}_{1}$ of $12 \%$ or more and $200 \mathrm{~mL}$ or more following administration of bronchodilator

${ }^{c}$ Defined as all patients randomized to treatment who did not have a history of using either the ELLIPTA or the Respimat inhaler device

${ }^{\mathrm{d}}$ Continued use of rescue albuterol therapy was permitted during the study, but other maintenance medications were excluded.

${ }^{\mathrm{e}}$ Glycopyrronium/indacaterol (13, 6\%), umeclidinium/vilanterol (10,4\%), tiotropium/olodaterol (6, 3\%), and aclidinium/formoterol (1, less than $1 \%)$

noninferiority margins [ $175 \mathrm{~mL}$ vs $122 \mathrm{~mL}$; LS mean difference $53 \mathrm{~mL}(95 \%$ CI $26-80 \mathrm{~mL})$; $p<0.001]$. In the ITT population, UMEC/VI demonstrated efficacy superior to that of TIO/OLO for trough $\mathrm{FEV}_{1}$ at week 8 [180 mL vs $128 \mathrm{~mL}$; LS mean difference $52 \mathrm{~mL}$ (95\% CI 28-77 mL); $p<0.001$; Table 2, Fig. 2]. In addition, a greater number of patients achieved a clinically meaningful increase in trough $\mathrm{FEV}_{1}$ (100 mL or more from baseline) with UMEC/VI compared with TIO/OLO at both week 4 and week 8 (ITT population; Table 2). Within-patient differences between UMEC/VI and $\mathrm{TIO} / \mathrm{OLO}$ in trough $\mathrm{FEV}_{1}$ response at week 8 are presented descriptively in Fig. 3. Overall, $52 \%$ of individuals achieved a clinically meaningful increase $\left(100 \mathrm{~mL}\right.$ or more) in trough $\mathrm{FEV}_{1}$ from baseline with UMEC/VI compared with TIO/OLO, 29\% of individuals showed similar clinical benefits for both treatments (less than 100-mL difference), and 19\% achieved a clinically meaningful increase $(100 \mathrm{~mL}$ or more) with TIO/OLO compared with UMEC/VI.

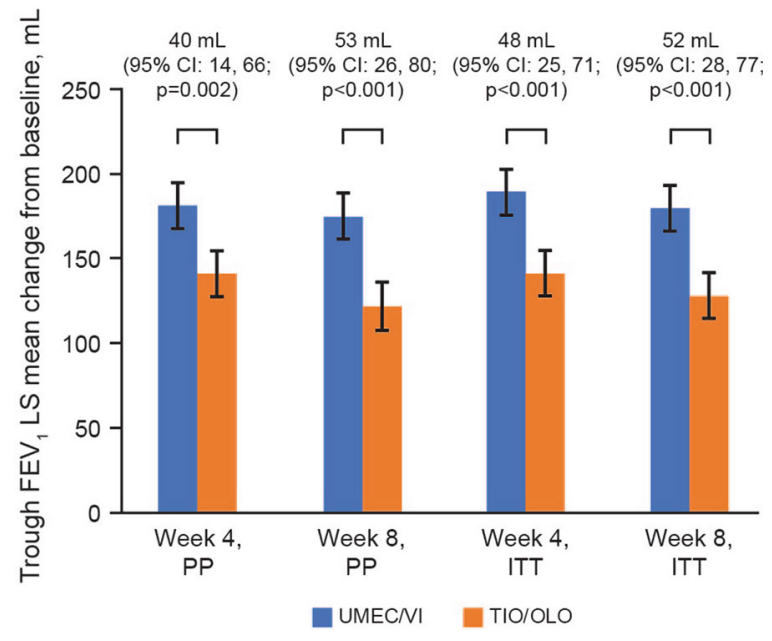

Fig. 2 Change from baseline in trough forced expiratory volume in $1 \mathrm{~s}\left(\mathrm{FEV}_{1}\right)$ with time for the per-protocol (PP) (see also Table S2) and intent-to-treat (ITT) populations. Error bars represent standard errors. CI confidence interval, LS least squares, TIO/OLO tiotropium/olodaterol $(5 / 5 \mu \mathrm{g}), \quad \mathrm{UMEC} / \mathrm{VI}$ umeclidinium/vilanterol $(62.5 / 25 \mu \mathrm{g})$ 


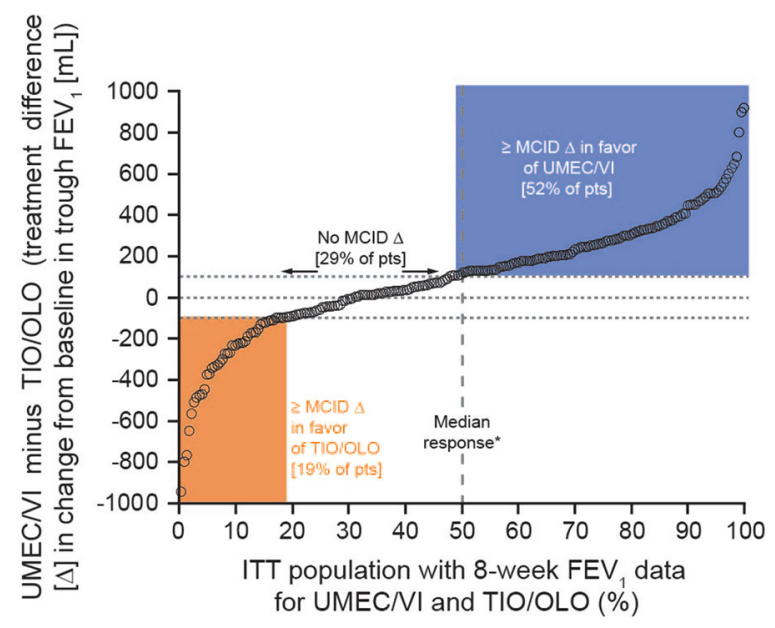

Fig. 3 Distribution of the treatment differences observed in all individual patients for the change from baseline in trough forced expiratory volume in $1 \mathrm{~s}\left(\mathrm{FEV}_{1}\right)$ at week 8 [umeclidinium/vilanterol, 62.5/25 $\mu \mathrm{g}$ (UMEC/VI), minus tiotropium/olodaterol, $5 / 5 \mu \mathrm{g}$ (TIO/OLO)] for the intent-to-treat (ITT) population. $\Delta$ treatment difference in individual patients (UMEC/VI minus TIO/OLO), MCID minimal clinically important difference in trough $\mathrm{FEV}_{1}(100 \mathrm{~mL})$, pts patients, asterisk median treatment difference of $120 \mathrm{~mL}$ in favor of UMEC/VI

Statistically significant increases in trough $\mathrm{FEV}_{1}$ were also observed with UMEC/VI compared with TIO/OLO at week 4 (PP and ITT populations; Fig. 2), and in other lung volume parameters (FVC and IC) at weeks 4 and 8 (ITT population; all $p<0.05$; Table 2 ).

\section{Patient-Reported Outcomes}

The LS mean (standard error) rescue medication use during the 8-week study period was 1.51 (0.08) puffs per day for UMEC/VI and 1.77 (0.08) puffs per day for TIO/OLO. Patients receiving UMEC/VI used statistically significantly less rescue medication during the study compared with those receiving TIO/OLO [Table $2 ;-0.25$ (95\% CI -0.37 to -0.14$)$ puffs per day; $p<0.001]$. There were no between-group differences in the percentage of rescue medication-free days (Table $2 ; p=0.152$ ).
A significant decrease in CAT score was observed with UMEC/VI compared with TIO/OLO at week 4 ( $p=0.042$; Table 2$)$, but not at week $8(p=0.695$; Table 2$)$. No statistically significant differences were observed between treatment groups in the percentage of CAT responders at either week 4 or week 8 (Table 2 ).

The change from baseline in weekly E-RS $\mathrm{COPD}_{\mathrm{C}}$ total scores ranged from -1.79 to -1.61 in the UMEC/VI group and from -1.72 to -1.31 in the TIO/OLO group during the 8 weeks, with a statistically significant difference in favor of UMEC/VI observed at week 5 (Fig. $4 ; p=0.031$ ). The proportion of patients showing a clinically important treatment response for the $\mathrm{E}^{\mathrm{RS}} \mathrm{COPD}_{\mathrm{CO}}$ total score (a 2-unit or greater decrease from baseline) [25] varied by individual week from $33 \%$ to $41 \%$ with UMEC/VI and from 31 to $34 \%$ with TIO/OLO. The odds ratios for achieving a treatment response with UMEC/VI compared with TIO/OLO varied from 0.97 to 1.43 , with no statistically significant differences.

Inhaler ease of use data were in favor of UMEC/VI for each of the criteria analyzed (see the electronic supplementary material).

\section{Safety}

The AE profile was similar between treatment groups (25\% vs 31\% for UMEC/VI vs TIO/OLO; Table 3). The most frequently reported AEs were upper respiratory tract infections (viral or nonviral), cough, and diarrhea (Table 3). The incidence of COPD exacerbations was low and similar between treatment groups (Table 3; ITT population). On-treatment SAEs occurred in 1\% or less of patients in both treatment groups (Table 3), with one instance of rib fracture, hepatocellular carcinoma, and peripheral neuropathy in the UMEC/VI group, and one instance of acute myocardial infarction, catheter site hemorrhage, and hyperglycemia in the TIO/OLO group. No SAEs were considered related to the study drug by the investigator, and only one AE led to withdrawal from the study (peripheral neuropathy; UMEC/VI group). No 


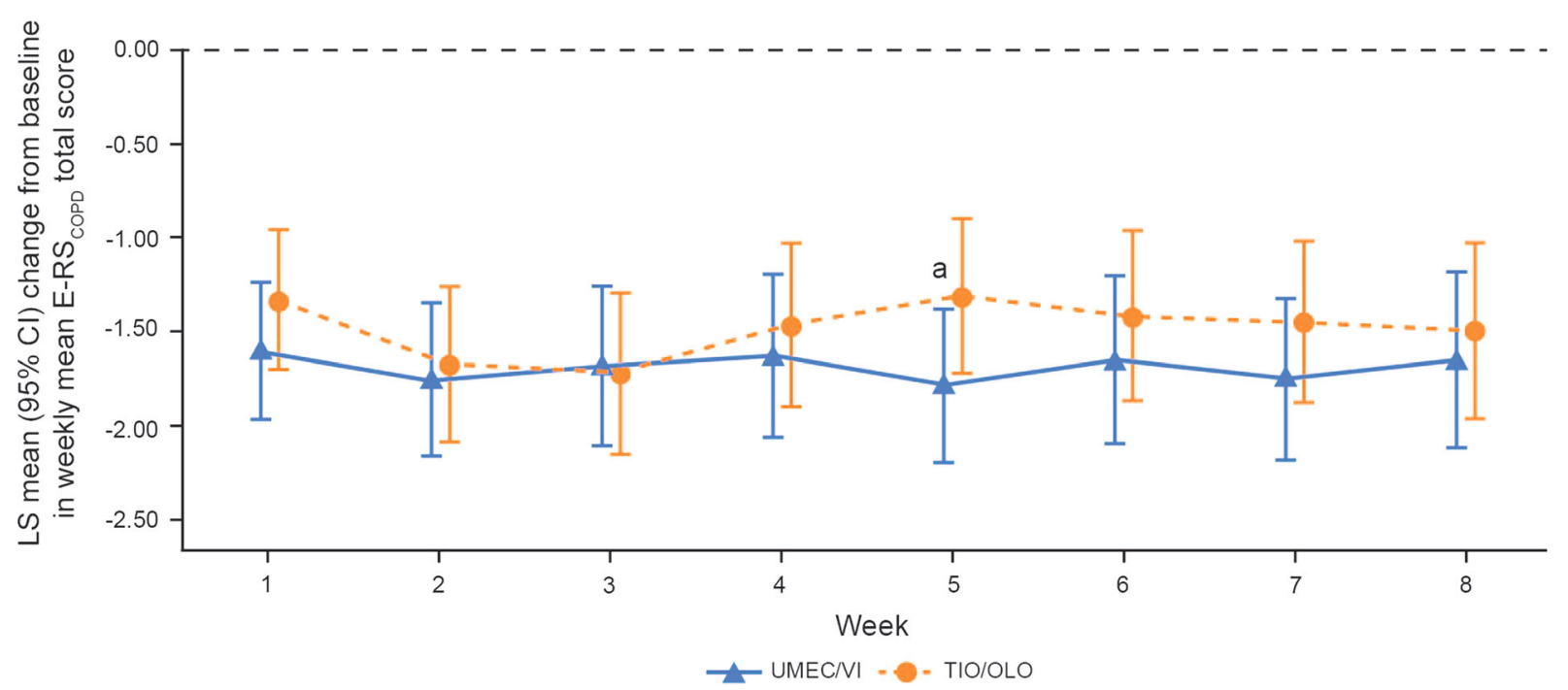

Fig. 4 Change from baseline in Evaluating Respiratory Symptoms-COPD (E-RS $\mathrm{COPD}_{\text {- }}$ ) total score (weeks 1-8) for the intent-to-treat population. Error bars represent the 95\% confidence interval (CI); a indicates $p<0.05$ for umeclidinium/vilanterol, 62.5/25 $\mu \mathrm{g}$ (UMEC/VI), versus

deaths or clinically meaningful changes in vital signs or clinical laboratory parameters were reported during the study.

\section{DISCUSSION}

This is the first direct comparison of the oncedaily fixed-dose LAMA/LABA combinations UMEC/VI and TIO/OLO in patients with symptomatic COPD. The results showed a statistically significant increase in trough $\mathrm{FEV}_{1}$, FVC, and IC, as well as a higher proportion of trough $\mathrm{FEV}_{1}$ responders $(100 \mathrm{~mL}$ or more increase from baseline), with UMEC/VI compared with TIO/OLO. A significantly greater decrease in rescue medication use was reported with UMEC/VI compared with TIO/OLO, but other patient-reported outcomes showed similar improvements with both UMEC/VI and TIO/OLO, with no consistent treatment difference detectable across all time periods. Both treatments had similar AE profiles.

Previous studies have indicated a potential efficacy gradient within the LAMA/LABA and LAMA classes. A recent, blinded, head-to-head study showed a significant $53-\mathrm{mL}$ increase in tiotropium/olodaterol, $5 / 5 \mu \mathrm{g}$ (TIO/OLO). Baseline E-RS COPD total score: UMEC/VI 12.02 (standard deviation 6.98); TIO/OLO 11.84 (standard deviation 6.55). LS least squares

trough $\mathrm{FEV}_{1}$ with $62.5 \mu \mathrm{g}$ UMEC compared with $18 \mu \mathrm{g}$ TIO in the ITT population (and $59 \mathrm{~mL}$ in the PP population) of patients with moderate-to-severe COPD [8], and indirect comparisons suggest that differences in efficacy may be present among LAMA/LABA combination therapies [16]. A systematic review by Calzetta et al. [16] showed an efficacy gradient ranging from 46 to $95 \mathrm{~mL}$ in trough $\mathrm{FEV}_{1}$ when comparing LAMA/LABAs with their monocomponents in patients with stable COPD. The smallest efficacy difference was observed with twice-daily administration of aclidinium/formoterol and the greatest difference was seen with once-daily administration of UMEC/VI [16]. A network meta-analysis by Schlueter et al. [17] also reported a statistically significant increase in trough $\mathrm{FEV}_{1}$ with UMEC/VI compared with twice-daily administration of aclidinium/formoterol, as well as a nonsignificant trend favoring UMEC/VI over TIO/OLO. A more recent and larger indirect Bayesian network meta-analysis by Sion et al. [18] reported a statistically significant increase in trough $\mathrm{FEV}_{1}$ with UMEC/VI compared with TIO/OLO at 12 weeks [18]. Significant increases in trough $\mathrm{FEV}_{1}$ at 24 weeks favoring UMEC/VI compared 
Table 2 Summary of change from baseline in lung function end points and patient-reported outcomes for the intent-to-treat population

\begin{tabular}{|c|c|c|c|c|c|}
\hline & Number & UMEC/VI & Number & TIO/OLO & $\begin{array}{l}\text { Difference/OR } \\
\text { UMEC/VI vs } \\
\text { TIO/OLO }\end{array}$ \\
\hline \multicolumn{6}{|l|}{ Trough $\mathrm{FEV}_{1}(\mathrm{~mL})$} \\
\hline Baseline, mean ${ }^{\mathrm{a}}$ & 234 & $1539(453)$ & 229 & $1587(445)$ & - \\
\hline \multicolumn{6}{|l|}{ Change from baseline to } \\
\hline Week 4 & 231 & $189(13)$ & 224 & $141(13)$ & $48(25-71)^{c}$ \\
\hline Week 8 & 225 & $180(13)$ & 224 & $128(13)$ & $52(28-77)^{\mathrm{c}}$ \\
\hline \multicolumn{6}{|l|}{ Trough $\mathrm{FEV}_{1}$ responders } \\
\hline Week 4 & 234 & $162(69 \%)$ & 227 & $116(51 \%)$ & OR: $2.09(1.39-3.14)^{c}$ \\
\hline Week 8 & 234 & $154(66 \%)$ & 229 & $109(48 \%)$ & OR: $2.05(1.34-3.14)^{c}$ \\
\hline \multicolumn{6}{|l|}{$\mathrm{FVC}(\mathrm{mL})$} \\
\hline Baseline, mean ${ }^{\mathrm{a}}$ & 234 & $2808(822)$ & 229 & $2863(799)$ & - \\
\hline \multicolumn{6}{|l|}{ Change from baseline to } \\
\hline Week 4 & 231 & $214(18)$ & 224 & $174(18)$ & $40(5-75)^{\mathrm{d}}$ \\
\hline Week 8 & 225 & $202(18)$ & 224 & $135(18)$ & $67(34-100)^{c}$ \\
\hline \multicolumn{6}{|l|}{ IC $(\mathrm{mL})$} \\
\hline Baseline, mean ${ }^{\mathrm{a}}$ & 227 & $2355(620)$ & 224 & $2379(603)$ & - \\
\hline \multicolumn{6}{|l|}{ Change from baseline to } \\
\hline Week 4 & 223 & $164(17)$ & 215 & $112(18)$ & $52(16-88)^{\mathrm{e}}$ \\
\hline Week 8 & 212 & $169(17)$ & 212 & $122(17)$ & $47(14-81)^{\mathrm{e}}$ \\
\hline $\begin{array}{l}\text { Baseline rescue medication use } \\
\text { (puffs/day), mean }{ }^{\mathrm{a}}\end{array}$ & 222 & $2.65(3.27)$ & 217 & $2.26(2.81)$ & - \\
\hline $\begin{array}{l}\text { Change from baseline in rescue } \\
\text { medication use (weeks 1-8) } \\
\text { (puffs/day) }\end{array}$ & 222 & $-0.94(0.08)$ & 217 & $-0.68(0.08)$ & $-0.25(-0.37 \text { to }-0.14)^{\mathrm{c}}$ \\
\hline $\begin{array}{l}\text { Baseline rescue medication-free } \\
\text { days, mean }{ }^{\mathrm{a}}\end{array}$ & 222 & $40.08(44.54)$ & 217 & $44.76(44.13)$ & - \\
\hline $\begin{array}{l}\text { Change from baseline in rescue } \\
\text { medication-free days (weeks 1-8) }\end{array}$ & 222 & $8.04(2.14)$ & 217 & $6.13(2.15)$ & $1.91(-0.71$ to 4.53$)$ \\
\hline \multicolumn{6}{|l|}{ CAT score } \\
\hline Baseline, mean ${ }^{a}$ & 233 & $18.03(7.40)$ & 225 & $17.48(7.17)$ & - \\
\hline \multicolumn{6}{|l|}{ Change from baseline to } \\
\hline Week 4 & 230 & $-1.60(0.28)$ & 220 & $-1.01(0.29)$ & $-0.59(-1.16 \text { to }-0.02)^{d}$ \\
\hline Week 8 & 221 & $-1.38(0.28)$ & 220 & $-1.26(0.28)$ & $-0.11(-0.68$ to 0.45$)$ \\
\hline
\end{tabular}


Table 2 continued

\begin{tabular}{|c|c|c|c|c|c|}
\hline & Number & UMEC/VI & Number & TIO/OLO & $\begin{array}{l}\text { Difference/OR } \\
\text { UMEC/VI vs } \\
\text { TIO/OLO }\end{array}$ \\
\hline \multicolumn{6}{|c|}{ CAT responders } \\
\hline Week 4 & 231 & $107(46 \%)$ & 222 & $86(39 \%)$ & OR: $1.25(0.85-1.82)$ \\
\hline Week 8 & 233 & $107(46 \%)$ & 225 & $94(42 \%)$ & OR: $1.05(0.72-1.55)$ \\
\hline \multicolumn{6}{|c|}{$\begin{array}{l}\text { All changes from baseline are presented as the least squares mean (standard error) change from baseline, unless otherwise } \\
\text { stated. Negative COPD Assessment Test (CAT) scores indicate clinical improvement. CAT responders were defined as } \\
\text { those with a decrease of } 2 \text { units or more from baseline [baseline CAT score, umeclidinium/vilanterol (UMEC/VI; 62.5/ } \\
25 \mu \mathrm{g}) 18.03 \text { (standard deviation } 7.40) \text {, tiotropium/olodaterol (TIO/OLO; } 5 / 5 \mu \mathrm{g} \text { ) 17.48 (standard deviation } 7.17) \text { ]. } \\
\text { Baseline rescue medication use: UMEC/VI }(62.5 / 25 \mu \mathrm{g}) 2.65 \text { (standard deviation 3.27); TIO/OLO }(5 / 5 \mu \mathrm{g}) 2.26 \text { (standard } \\
\text { deviation } 2.81 \text { ). } \\
C I \text { confidence interval, COPD chronic obstructive pulmonary disease, FEV forced expiratory volume in } 1 \mathrm{~s}, F V C \text { forced } \\
\text { vital capacity, } I C \text { inspiratory capacity, OR odds ratio } \\
\text { a The standard deviation is given in parentheses } \\
\text { b The } 95 \% \text { confidence interval is given in parentheses } \\
\text { c } p<0.001 \\
\text { d } p<0.05 \\
\text { e } p<0.01\end{array}$} \\
\hline
\end{tabular}

with TIO/OLO were also observed in patients with moderate airflow limitation or those not receiving ICS therapy $(45-59 \mathrm{~mL})$. The $52-\mathrm{mL}$ increase in trough $\mathrm{FEV}_{1}$ with $\mathrm{UMEC/VI}$ versus TIO/OLO observed in this study supports these earlier analyses, and confirms an efficacy gradient exists within the LAMA/LABA class with respect to lung function (UMEC/VI > TIO/OLO). This is additional to the 60-mL increase in trough $\mathrm{FEV}_{1}$ reported with $\mathrm{TIO} / \mathrm{OLO}$ compared with $\mathrm{TIO}$ at 24 weeks in the TOnado 1 and TOnado 2 pivotal trials (71 and $50 \mathrm{~mL}$, respectively) [12].

Although the minimal clinically meaningful difference from baseline in trough $\mathrm{FEV}_{1}$ is deemed to be $100 \mathrm{~mL}$ [30], this was determined on the basis of comparisons of active treatments with placebo. It is possible that smaller differences between active therapies could be associated with changes in symptoms and health status reported by the patient. In this study, the observed significant additional increase in trough $\mathrm{FEV}_{1}$ and IC at 8 weeks with UMEC/VI compared with TIO/OLO was reflected in a significant added benefit in favor of UMEC/VI observed in reduced rescue medication use (puffs per day); however, it was not reflected in other patient-reported outcomes.

In any given COPD population with limited bronchodilator reversibility, potentially modest incremental mean treatment differences are likely when two active therapies are compared. The crossover design of this study not only allowed patients to receive both LAMA/LABA combinations (in a random sequence) to estimate the overall mean incremental efficacy difference in trough $\mathrm{FEV}_{1}$, but also allowed the quantification of the number of individual patients who experienced a clinically meaningful $(100 \mathrm{~mL}$ or more) treatment difference from baseline between the two LAMA/LABA combinations. Patients receiving UMEC/VI had twofold increased odds of experiencing a clinically meaningful increase from baseline in trough $\mathrm{FEV}_{1}$ at both week 4 and week 8 compared with those receiving TIO/OLO. In addition, individual patient responses demonstrated that $52 \%$ of patients reported a more than 100-mL better increase with UMEC/VI compared with TIO/OLO, with only $19 \%$ achieving a similar magnitude of benefit in the opposite direction. Achieving this clinically 
Table 3 Summary of chronic obstructive pulmonary disease (COPD) exacerbations, adverse events (AEs; occurring in three or more patients overall), and serious AEs (SAEs) for the intent-to-treat population

\begin{tabular}{lcc}
\hline & UMEC/VI $(\boldsymbol{N}=\mathbf{2 3 5})$ & TIO/OLO $(\boldsymbol{N}=\mathbf{2 3 0})$ \\
\hline COPD exacerbations & $217(92 \%)$ & $211(92 \%)$ \\
0 & $15(6 \%)$ & $18(8 \%)$ \\
1 & $3(1 \%)$ & $1(<1 \%)$ \\
2 & $59(25 \%)$ & $71(31 \%)$ \\
Any AE & $11(5 \%)$ & $14(6 \%)$ \\
Viral URTI & $8(3 \%)$ & $7(3 \%)$ \\
URTI & $3(1 \%)$ & $3(1 \%)$ \\
Cough & $3(1 \%)$ & $3(1 \%)$ \\
Diarrhea & $3(1 \%)$ & $2(<1 \%)$ \\
Hypertension & $1(<1 \%)$ & $4(2 \%)$ \\
Sinusitis & $1(<1 \%)$ & $3(1 \%)$ \\
Headache & $2(<1 \%)$ & $1(<1 \%)$ \\
Back pain & $2(<1 \%)$ & $1(<1 \%)$ \\
Dizziness & $1(<1 \%)$ & $2(<1 \%)$ \\
Dry mouth & $1(<1 \%)$ & $2(<1 \%)$ \\
Oropharyngeal pain & $3(1 \%)$ & $2(<1 \%)$ \\
Any SAE & &
\end{tabular}

TIO/OLO tiotropium/olodaterol $(5 / 5 \mu \mathrm{g}), U M E C / V I$ umeclidinium/vilanterol $(62.5 / 25 \mu \mathrm{g})$, URTI upper respiratory tract infection

important treatment goal more frequently with UMEC/VI compared with TIO/OLO is likely to be important in COPD, as it has been shown over longer assessment periods to be associated with a reduced risk of future exacerbations, with a 100-mL increase in trough $\mathrm{FEV}_{1}$ from the baseline resulting in an estimated $12-21 \%$ decrease in exacerbation rates, with a $28-30 \%$ rate reduction for responders compared with nonresponders [31-34]. An improved likelihood of achieving clinically relevant improvements in long-term health status [32, 33] and the potential to prevent longer-term clinically relevant deteriorations in lung function and health status have also been linked to improved bronchodilation [35-39]. The increase in trough $\mathrm{FEV}_{1}$ observed with UMEC/VI compared with TIO/OLO was also supported by similar observations on other lung volume parameters (FVC and IC) at 4 and 8 weeks. Increases in resting IC suggest a beneficial effect on static lung hyperinflation, an important aspect of COPD that is associated with increased dyspnea and a reduced ability to perform activities of daily living [40-42]. Although dyspnea was not directly assessed in this study, other bronchodilator studies have shown associations between similar improvements in lung function and volumes and reductions in breathlessness $[12,43]$.

The benefits of aiming for maximal bronchodilation must always be balanced against the increased potential for AEs and SAEs. In this study, the greater improvements in lung function seen with UMEC/VI compared with TIO/OLO were not at the expense of any increase in $\mathrm{AE}$ reporting. Indeed, both treatment regimens were well tolerated, with similar 
safety profiles. As a recent network meta-analysis by Oba et al. [44] has also reported that the LAMA/LABA class is as well tolerated as LAMA monotherapy, and similar findings have been reported in randomized controlled trials of UMEC/VI compared with TIO [10], these findings are reassuring.

In this study, the inclusion of highly symptomatic patients with a modified Medical Research Council Dyspnoea Scale score of 2 or greater and a postbronchodilator $\mathrm{FEV}_{1}$ of $50-70 \%$ of the predicted value [Global Initiative for Chronic Obstructive Lung Disease (GOLD) stage 2] focused the study on patients appropriate for early use of dual bronchodilator therapy who were more likely to be responsive to treatment, thereby facilitating better detection of within-class efficacy differences. Likewise, the exclusion of concomitant ICS treatment, in line with the current GOLD treatment paradigm favoring LAMA/LABA use before the addition of ICS therapy [4], also limited confounding of the maximum bronchodilator response, providing greater capacity to detect within-class efficacy differences. These factors support the robustness of the findings, and should be considered in future comparative studies of LAMA/LABA treatments.

The limitations of this study include those associated with the study design, such as the open-label administration of treatments, no placebo arm, and the potentially short 8-week study duration. Open-label treatment has the potential to introduce bias, particularly in subjective patient-reported efficacy assessments, but it was not possible to source placebo Respimat inhalers from Boehringer Ingelheim to allow a double-blind, double-dummy study to be performed. However, to mitigate any potential for bias on the objectively assessed primary outcome measure, the technicians performing spirometry were blinded to treatment allocation within each study period. It is also notable that the magnitude of the treatment difference for the primary end point was fully in line with expectations seen from indirect treatment comparisons of double-blind trials $[8,18]$. The 8 -week study duration was sufficient to allow robust assessments of bronchodilator response, with a plateau in the responses detected after 4 weeks with both treatments. However, it could be argued that the study duration was too short to assess differences in longer-term outcomes such as the rate of exacerbations and changes in quality of life over time. Nevertheless, given the comparison in this study is between two bronchodilators, clinically meaningful increases in trough $\mathrm{FEV}_{1}$ in the first 8 weeks, twofold increased odds of achieving a clinically meaningful level of response, and the reported impact of this level of response on future reductions in annual exacerbation rates suggest the potential for longer-term efficacy differences [31].

\section{CONCLUSION}

In this first direct comparison of the once-daily fixed-dose LAMA/LABA combinations UMEC/VI and TIO/OLO, superiority was observed with UMEC/VI for the primary end point of trough $\mathrm{FEV}_{1}$ at week 8 in patients with symptomatic COPD. This finding confirms the results of previous indirect LAMA/LABA comparisons, and shows that an efficacy gradient exists within the LAMA/LABA class.

\section{ACKNOWLEDGEMENTS}

Editorial support (in the form of writing assistance during development of the initial draft, assembling tables and figures, collating authors' comments, grammatical editing, and referencing) was provided by Chrystelle Rasamison and Stuart Wakelin (contractor), at Fishawack Indicia Ltd, UK, and was funded by GlaxoSmithKline.

This study was funded by GlaxoSmithKline (study number 204990). The funders of the study had a role in study design, data analysis, data interpretation, and writing of the report, and are also funding the article processing charges and open access fee.

All named authors meet the International Committee of Medical Journal Editors criteria for authorship for this article, take responsibility for the integrity of the work as a whole, contributed to the writing and reviewing of the 
manuscript, and have given final approval for the version to be published. All authors had full access to all of the data in this study and take complete responsibility for the integrity of the data and accuracy of the data analysis.

GJF and BAN were involved in the acquisition of data and data analysis and interpretation. ARS, DAL, SP, IN, JHR, NB, and CC were involved in the conception and design of the study and data analysis and interpretation. LT was involved in the conception and design of the study, acquisition of data, and data analysis and interpretation.

Disclosures. A.R. Sousa is an employee of GlaxoSmithKline and holds stock and shares in GlaxoSmithKline.

C. Compton is an employee of GlaxoSmithKline and holds stock and shares in GlaxoSmithKline.

D. A. Lipson is an employee of GlaxoSmithKline and holds stock and shares in GlaxoSmithKline.

I. Naya is an employee of GlaxoSmithKline and holds stock and shares in GlaxoSmithKline.

J.H Riley is an employee of GlaxoSmithKline and holds stock and shares in GlaxoSmithKline.

$\mathrm{N}$. Barnes is an employee of GlaxoSmithKline and holds stock and shares in GlaxoSmithKline.

S. Patel is an employee of GlaxoSmithKline and holds stock and shares in GlaxoSmithKline.

L. Tombs is a contingent worker on assignment at GlaxoSmithKline. B. Alcázar Navarrete has received personal fees and nonfinancial support from GlaxoSmithKline, grants, personal fees, and nonfinancial support from Novartis AG, personal fees and nonfinancial support from Boehringer Ingelheim, personal fees and nonfinancial support from Chiesi, grants, personal fees, and nonfinancial support from Laboratorios Menarini, personal fees from Gebro, and personal fees from AstraZeneca outside the submitted work. In addition, B. Alcázar Navarrete has a patent (P201730724) pending. G.J.
Feldman does not have any conflicts of interest to declare.

Compliance with Ethics Guidelines. The study was conducted in accordance with International Conference on Harmonisation of Technical Requirements for Registration of Pharmaceuticals for Human Use good clinical practice guidelines and the principles of the Declaration of Helsinki. The protocol was reviewed and approved by all appropriate institutional review boards or independent ethics committees [Ethik-Komission (Germany), Comité Ético de Investigación (Spain), Chesapeake IRB (USA), and United Kingdom Ethics Committee]. All patients provided written informed consent before study participation.

Availability of Data and Material. The datasets used and/or analyzed during the current study are available from the corresponding author on reasonable request.

Open Access. This article is distributed under the terms of the Creative Commons Attribution-NonCommercial 4.0 International License (http://creativecommons.org/licenses/ by-nc/4.0/), which permits any noncommercial use, distribution, and reproduction in any medium, provided you give appropriate credit to the original author(s) and the source, provide a link to the Creative Commons license, and indicate if changes were made.

\section{REFERENCES}

1. Lozano R, Naghavi M, Foreman K, Lim S, Shibuya K, Aboyans V, et al. Global and regional mortality from 235 causes of death for 20 age groups in 1990 and 2010: a systematic analysis for the Global Burden of Disease Study 2010. Lancet. 2012;380:2095-128.

2. Ehteshami-Afshar S, FitzGerald JM, Doyle-Waters MM, Sadatsafavi M. The global economic burden of asthma and chronic obstructive pulmonary disease. Int J Tuberc Lung Dis. 2016;20:11-23.

3. Lopez-Campos JL, Tan W, Soriano JB. Global burden of COPD. Respirology. 2016;21:14-23. 
4. Global Initiative for Chronic Obstructive Lung Disease. Global strategy for the diagnosis,management and prevention of chronic obstructive pulmonary disease (2017). http://goldcopd.org/gold2017-global-strategy-diagnosis-management-preven tion-copd/. Accessed Feb 2017.

5. Cazzola M, Page CP, Calzetta L, Matera MG. Pharmacology and therapeutics of bronchodilators. Pharmacol Rev. 2012;64:450-504.

6. Tashkin DP, Cooper CB. The role of long-acting bronchodilators in the management of stable COPD. Chest. 2004;125:249-59.

7. Tashkin DP, Ferguson GT. Combination bronchodilator therapy in the management of chronic obstructive pulmonary disease. Respir Res. 2013;14:49.

8. Feldman G, Maltais F, Khindri S, Vahdati-Bolouri M, Church A, Fahy WA, et al. A randomized, blinded study to evaluate the efficacy and safety of umeclidinium $62.5 \mathrm{mcg}$ compared with tiotropium $18 \mathrm{mcg}$ in patients with COPD. Int J Chron Obstruct Pulmon Dis. 2016;11:719-30.

9. Bateman ED, Ferguson GT, Barnes N, Gallagher N, Green Y, Henley M, et al. Dual bronchodilation with QVA149 versus single bronchodilator therapy: the SHINE study. Eur Respir J. 2013;42:1484-94.

10. Decramer $M$, Anzueto A, Kerwin E, Kaelin T, Richard N, Crater G, et al. Efficacy and safety of umeclidinium plus vilanterol versus tiotropium, vilanterol, or umeclidinium monotherapies over 24 weeks in patients with chronic obstructive pulmonary disease: results from two multicentre, blinded, randomised controlled trials. Lancet Respir Med. 2014;2:472-86.

11. Maleki-Yazdi MR, Kaelin T, Richard N, Zvarich M, Church A. Efficacy and safety of umeclidinium/vilanterol $62.5 / 25 \mathrm{mcg}$ and tiotropium $18 \mathrm{mcg}$ in chronic obstructive pulmonary disease: results of a 24-week, randomized, controlled trial. Respir Med. 2014;108:1752-60.

12. Buhl R, Maltais F, Abrahams R, Bjermer L, Derom E, Ferguson $G$, et al. Tiotropium and olodaterol fixed-dose combination versus mono-components in COPD (GOLD 2-4). Eur Respir J. 2015;45:969-79.

13. ZuWallack R, Allen L, Hernandez G, Ting N, Abrahams R. Efficacy and safety of combining olodaterol Respimat $^{\circledR}$ and tiotropium HandiHaler ${ }^{\mathbb{B}}$ in patients with COPD: results of two randomized, double-blind, active-controlled studies. Int J Chron Obstruct Pulmon Dis. 2014;9:1133-44.

14. Singh D, Ferguson GT, Bolitschek J, Gronke L, Hallmann $\mathrm{C}$, Bennett $\mathrm{N}$, et al.
Tiotropium + olodaterol shows clinically meaningful improvements in quality of life. Respir Med. 2015;109:1312-9.

15. Wedzicha JA, Decramer M, Ficker JH, Niewoehner DE, Sandstrom T, Taylor AF, et al. Analysis of chronic obstructive pulmonary disease exacerbations with the dual bronchodilator QVA149 compared with glycopyrronium and tiotropium (SPARK): a randomised, double-blind, parallel-group study. Lancet Respir Med. 2013;1:199-209.

16. Calzetta L, Rogliani P, Matera MG, Cazzola M. A systematic review with meta-analysis of dual bronchodilation with LAMA/LABA for the treatment of stable COPD. Chest. 2016;149:1181-96.

17. Schlueter $M$, Gonzalez-Rojas N, Baldwin $M$, Groenke L, Voss F, Reason T. Comparative efficacy of fixed-dose combinations of long-acting muscarinic antagonists and long-acting $\beta 2$-agonists: a systematic review and network meta-analysis. Ther Adv Respir Dis. 2016;10:89-104.

18. Sion KYJ, Huisman EL, Punekar YS, Naya I, Ismaila AS. A network meta-analysis of long-acting muscarinic antagonist (LAMA) and long-acting $\beta_{2}$-agonist (LABA) combinations in COPD. Pulm Ther. 2017. doi:10.1007/s41030-017-0048-0.

19. GlaxoSmithKline. ANORO ${ }^{\mathrm{TM}}$ ELLIPTA $^{\circledR}$. Highlights of prescribing information. https://www.acces sdata.fda.gov/drugsatfda_docs/label/2013/203975s 000lbl.pdf. Accessed 9 May 2017.

20. Boehringer Ingelheim International GmbH. STIOLTO $^{\mathrm{TM}}$ RESPIMAT $^{\circledR}$. Highlights of prescribing information. https://www.accessdata.fda.gov/drugsa tfda_docs/label/2015/206756s001lbl.pdf. Accessed 9 May 2017.

21. Celli BR, MacNee W, Force AET. Standards for the diagnosis and treatment of patients with COPD: a summary of the ATS/ERS position paper. Eur Respir J. 2004;23:932-46.

22. Hankinson JL, Odencrantz JR, Fedan KB. Spirometric reference values from a sample of the general US population. Am J Respir Crit Care Med. 1999; 159:179-87.

23. Mahler DA, Wells CK. Evaluation of clinical methods for rating dyspnea. Chest. 1988;93:580-6.

24. Jones PW, Harding G, Berry P, Wiklund I, Chen WH, Kline Leidy N. Development and first validation of the COPD Assessment Test. Eur Respir J. 2009;34:648-54.

25. Leidy NK, Murray LT, Monz BU, Nelsen L, Goldman $\mathrm{M}$, Jones $\mathrm{PW}$, et al. Measuring respiratory symptoms of COPD: performance of the 
EXACT-respiratory Symptoms Tool (E-RS) in three clinical trials. Respir Res. 2014;15:124.

26. Leidy NK, Sexton CC, Jones PW, Notte SM, Monz BU, Nelsen L, et al. Measuring respiratory symptoms in clinical trials of COPD: reliability and validity of a daily diary. Thorax. 2014;69:443-9.

27. Chapman KR, Beeh KM, Beier J, Bateman ED, D'Urzo A, Nutbrown R, et al. A blinded evaluation of the efficacy and safety of glycopyrronium, a once-daily long-acting muscarinic antagonist, versus tiotropium, in patients with COPD: the GLOW5 study. BMC Pulm Med. 2014;14:4.

28. Agusti A, de Teresa L, De Backer W, Zvarich MT, Locantore N, Barnes N, et al. A comparison of the efficacy and safety of once-daily fluticasone furoate/ vilanterol with twice-daily fluticasone propionate/ salmeterol in moderate to very severe COPD. Eur Respir J. 2014;43:763-72.

29. Ichinose $M$, Fujimoto $T$, Fukuchi Y. Tiotropium 5 microg via Respimat and 18 microg via HandiHaler; efficacy and safety in Japanese COPD patients. Respir Med. 2010;104:228-36.

30. Donohue JF. Minimal clinically important differences in COPD lung function. COPD. 2005;2:111-24.

31. Calverley PM, Postma DS, Anzueto AR, Make BJ, Eriksson G, Peterson S, et al. Early response to inhaled bronchodilators and corticosteroids as a predictor of 12-month treatment responder status and COPD exacerbations. Int J Chron Obstruct Pulmon Dis. 2016;11:381-90.

32. Jones PW, Donohue JF, Nedelman J, Pascoe S, Pinault $G$, Lassen C. Correlating changes in lung function with patient outcomes in chronic obstructive pulmonary disease: a pooled analysis. Respir Res. 2011;12:161.

33. Westwood M, Bourbeau J, Jones PW, Cerulli A, Capkun-Niggli G, Worthy G. Relationship between FEV1 change and patient-reported outcomes in randomised trials of inhaled bronchodilators for stable COPD: a systematic review. Respir Res. 2011;12:40.

34. Zider AD, Wang X, Buhr RG, Sirichana W, Barjaktarevic IZ, Cooper CB. Reduced COPD exacerbation risk correlates with improved FEV1: a meta-regression analysis. Chest. 2017;152(3):494-501.

35. Singh D. New combination bronchodilators for chronic obstructive pulmonary disease: current evidence and future perspectives. Br J Clin Pharmacol. 2015;79:695-708.

36. Naya I, Tombs L, Mullerova H, Compton C, Jones P. Long-term outcome following first clinically important deterioration in COPD. Eur Respir J. 2016;48:PA304.

37. Anzueto AR, Vogelmeier CF, Kostikas K, Mezzi K, Fucile S, Bader G, et al. The effect of indacaterol/ glycopyrronium versus tiotropium or salmeterol/ fluticasone on the prevention of clinically important deterioration in COPD. Int J Chron Obstruct Pulmon Dis. 2017;12:1325-37.

38. Maleki-Yazdi MR, Singh D, Anzueto A, Tombs L, Fahy WA, Naya I. Assessing short-term deterioration in maintenance-naive patients with COPD receiving umeclidinium/vilanterol and tiotropium: a pooled analysis of three randomized trials. Adv Ther. 2017;33:2188-99.

39. Singh D, Maleki-Yazdi MR, Tombs L, Iqbal A, Fahy WA, Naya I. Prevention of clinically important deteriorations in COPD with umeclidinium/vilanterol. Int $\mathrm{J}$ Chron Obstruct Pulmon Dis. 2016;11:1413-24.

40. Marin JM, Carrizo SJ, Gascon M, Sanchez A, Gallego B, Celli BR. Inspiratory capacity, dynamic hyperinflation, breathlessness, and exercise performance during the 6-min-walk test in chronic obstructive pulmonary disease. Am J Respir Crit Care Med. 2001;163:1395-9.

41. Pitta F, Troosters T, Spruit MA, Probst VS, Decramer M, Gosselink R. Characteristics of physical activities in daily life in chronic obstructive pulmonary disease. Am J Respir Crit Care Med. 2005;171:972-7.

42. Silva CS, Nogueira FR, Porto EF, Gazzotti MR, Nascimento OA, Camelier A, et al. Dynamic hyperinflation during activities of daily living in COPD patients. Chron Respir Dis. 2015;12:189-96.

43. Buhl R, Gessner C, Schuermann W, Foerster K, Sieder C, Hiltl S, et al. Efficacy and safety of once-daily QVA149 compared with the free combination of once-daily tiotropium plus twice-daily formoterol in patients with moderate-to-severe COPD (QUANTIFY): a randomised, non-inferiority study. Thorax. 2015;70:311-9.

44. Oba Y, Sarva ST, Dias S. Efficacy and safety of long-acting $\beta$-agonist/long-acting muscarinic antagonist combinations in COPD: a network meta-analysis. Thorax. 2016;71:15-25. 